\title{
Measurement of temperature and displacement with NiTi actuators under certain electrical conditions
}

\author{
Ersin Toptas ${ }^{1}$, Mehmet Fatih Celebi ${ }^{2}$, Sezgin Ersoy ${ }^{3}$ \\ Mechatronics Engineering Department, Marmara University, Istanbul, Turkey \\ ${ }^{2}$ Corresponding author \\ E-mail: ${ }^{1}$ etoptas@marmara.edu.tr, ${ }^{2}$ fatih.celebi@marmara.edu.tr, ${ }^{3}$ sersoy@marmara.edu.tr \\ Received 13 December 2020; received in revised form 8 March 2021; accepted 25 March 2021 \\ DOI https://doi.org/10.21595/jme.2021.21841 \\ D) Check for updates \\ Copyright $(0) 2021$ Ersin Toptas, et al. This is an open access article distributed under the Creative Commons Attribution License, which \\ permits unrestricted use, distribution, and reproduction in any medium, provided the original work is properly cited.
}

\begin{abstract}
In this study, various mechanical behaviors of a shape memory alloy, depending on different thermal and electrical conditions to be used in areas such as biomedical, aerospace and aeronautics. Temperature changes and length change rates under different electrical current values of a shape memory alloy named "nickel titanium", or "nitinol" (NiTi) has been observed. It has been seen that a $0.3 \mathrm{~mm}$ diameter wire can generate a force of $25 \mathrm{~N}$ while the material extends its linear measurement with a rate of $3.7 \mathrm{~mm} / \mathrm{s}$. It is observed that, under diverse constant electrical current values, the displacement and temperature relations of the nickel titanium wire is varying. It has empirically been seen that the nickel titanium alloy actuators are advantageous than their alternatives in terms of the generated strength to weight ratio and shape memory alloy materials can be used as actuators in industrial and biomedical applications.
\end{abstract}

Keywords: actuators, shape memory alloys, sma, nickel titanium, niti, nitinol, biocompatibility.

\section{Introduction}

The usage areas of Shape Memory Alloys (SMAs) are increasing day by day as a result of their superior features. These materials are materials that have the ability to return to their real shape or size by applying an appropriate heat procedure in cases where the geometry is distorted as a result of mechanical stress (Fig 1). SMAs find wide application areas in space researches, automotive industry, microelectromechanical and biomedical applications since these materials can return to their original shape or size by implementing a suitable heating procedure if their geometry is deformed because of being under mechanical stress. They also have extremely high resistance against corrosion and show excellent biocompability [1-5].

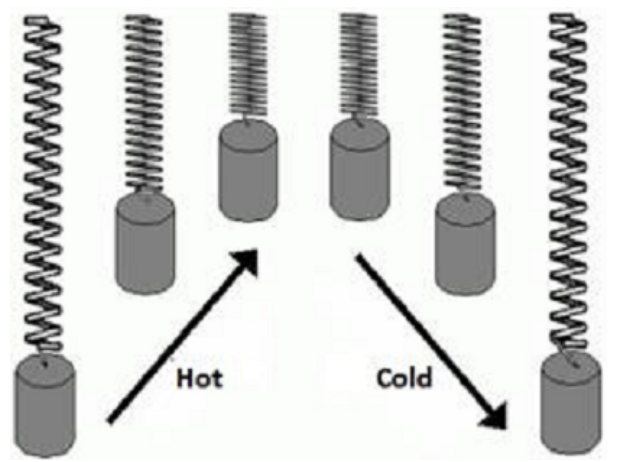

Fig. 1. Change of shape of a SMA metal with heat difference [3]

In order to design SMAs as actuators in systems, their structure must be well known. This material differs from normal materials when subjected to tensile and compression tests due to its unique feature in its structure. As a result of the phase changes in its structure, it shows superelesticity and shape memory properties. In addition, as shown in Fig. 2, when these alloys 
are heated because of shape changes, their atomic arrangements change as a result of phase changes in the material structure and return to their original shape. The reason for this is due to the martensite-austenite phase transformations occurring in the material structure (Fig. 2) $[7,8]$.

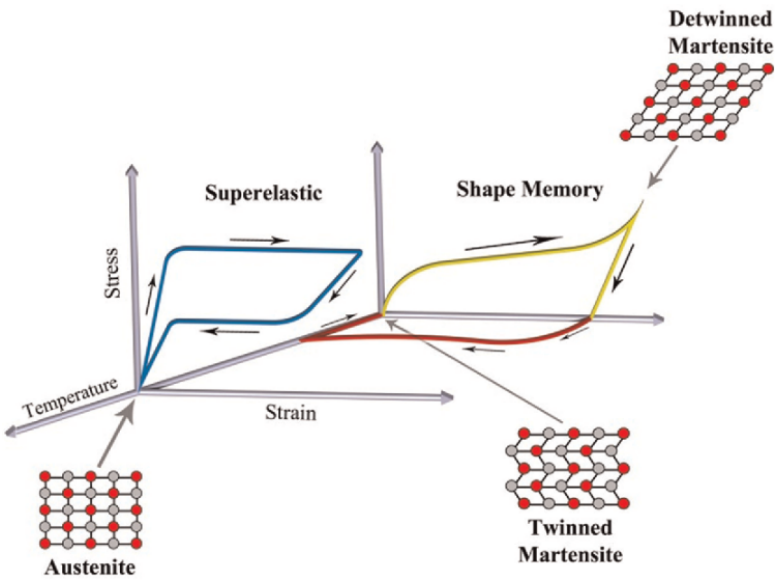

Fig. 2. Thermomechanical structures of SMAs [6]

SMAs are used in biomedical/medical applications, space researches, microelectromechanical systems, aircraft hydraulic systems, semiconductor gas tube connections, dental bracing components, satellite systems, thermostatic devices, on radiator blades of vehicles, and at exhaust outlet controllers, etc. [2, 9-12]. When choosing an SMA material, one of the most important factors is the compatibility of the material with the environment, thus, they have to have large workout capacity and great deformation capability without losing the capability to turn back to its original shape. These materials are being used in applications with low demand of response speed because of their high actuating ability, extensively. To create a design for a specific application, understanding the nature of the material and estimating its general system model is important. These materials have a complex structure with hystericizes, resistances, microstructure differences and super elasticity effects [13-15].

There are important criteria to design the actuators used in certain systems. If the actuator occupies too much volume or add too much extra weight in the design, it adversely effects the system, especially for the avionic and aerospace systems and vehicles. In these systems, actuators must fulfill their duty with as low volume and mass as possible. The actuators produced in the past are evaluated according to power to weight performance criterion [2, 16, 17]. Fig. 3 compares most of the actuators with respect to this criterion.

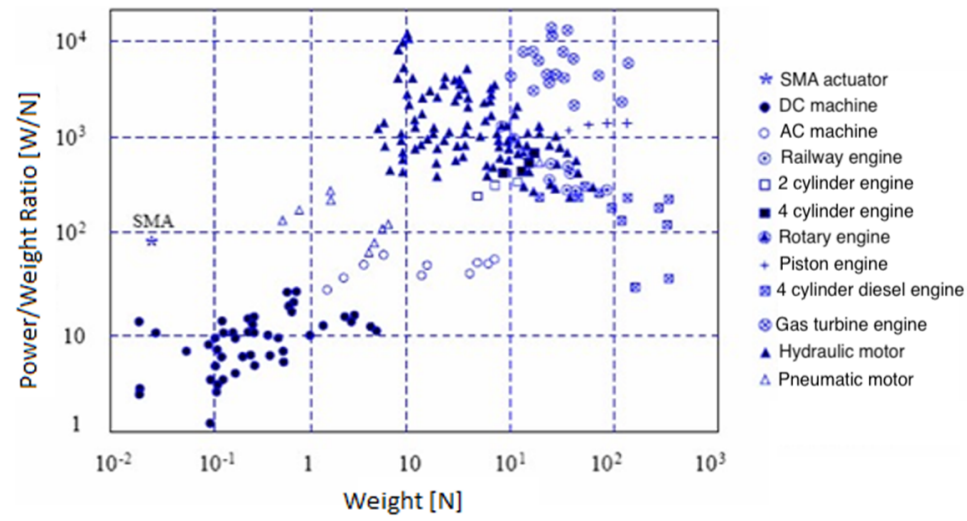

Fig. 3. Power to weight performances of various actuator types [12] 
If barriers are put in the process of returning to its previous shape, high tensions may occur up to $700 \mathrm{MPa}$, and the material starts to act like a muscle. Since this feature, they have important roles when implementing as prosthetic fingers in medical applications as shown in Fig. 4.

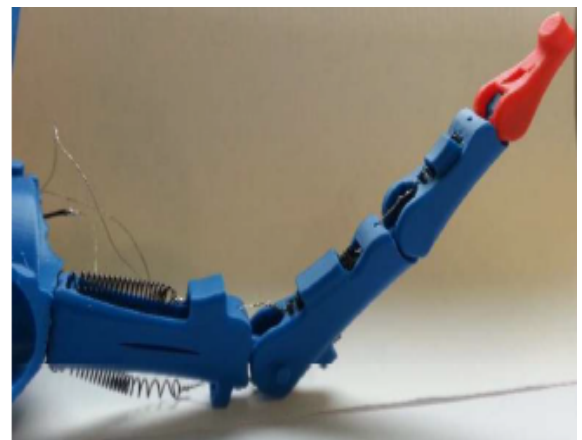

a) An implementation example of SMA to prosthetic finger

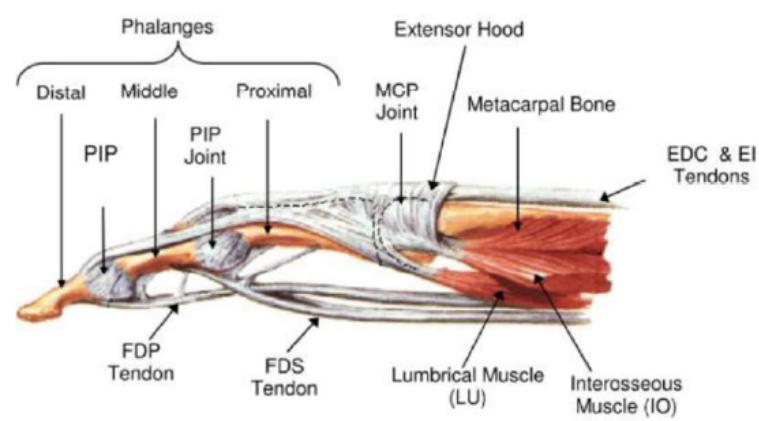

b) Anatomy of human finger

Fig. 4. A mechanical finger with SMA wires as muscles [15]

There are various studies available focused on force-deflection and strength of other materials, like concrete and steel bars $[19,20]$, however, since NiTis show super elastic properties by the changes within its internal structure, they have a high potential to be used as actuator alternatives in industrial applications. In this study, an elastic, lightweight, and thin SMA wire has been observed under varying electrical current values. The main purpose of this article is to examine an actuator with good power / weight performance that can be used instead of artificial muscle in humanoid robots.

\section{Material and method}

SMA materials are used as actuators in various fields due to their superior properties. In applications, the large unit deformation of this material, the power it produces as a result of phase transformations and the small volume or weight it has in response to this power provide a great advantage. NiTi alloys, which are SMA, have a wide range of use, especially in biomedical applications, thanks to their superior properties. These alloys are extremely resistant to corrosion and show excellent biocompatibility. For this reason, such materials can be used as artificial muscles in humanoid robots carried out in biomechanical applications. In this study, the mechanical behavior of a NiTi alloyed Shape Memory Alloy wire as an actuator was investigated. For this reason, SMA Nitinol wire with $\varnothing 0.3 \mathrm{~mm}$ diameter and $1200 \mathrm{~mm}$ length was used in our study and the material properties are given in Table 1.

In the experimental study, the mechanical behavior of $\mathrm{Ni}-\mathrm{Ti}$ alloyed wire under electric current for use in artificial muscle applications will be investigated. In the experiment, mechanical changes occur due to the phase transformations in the material structure of the Ni-Ti wire heated by electric current. With the experimental setup shown in the Fig. 5, the measurement of the displacement of the wire has been taken using a Linear Variable Displacement Transducer (LVDT), a force gauge, and a thermocouple as sensors, a data logger and a computer to collect and process the measured data, and a Direct Current (DC) power supply with an ammeter connected in series.

The mechanical attitudes of the NiTi SMA wire under the electrical current has been investigated in two stages. In the first stage, the force and resistance change of the wire under increasing current has been observed. In the second stage, the displacement amount of the wire under increasing current has been measured. The collected data has been saved and processed by the computer of the experimental setup and the kinetic and kinematic properties of the wire has been revealed. 
Table 1. Material properties of a Ø $0.3 \mathrm{~mm}, \mathrm{~L} 1200 \mathrm{~mm}$ NiTi Wire [18]

\begin{tabular}{|c|c|c|}
\hline \multicolumn{2}{|c|}{ Property } & Value \\
\hline \multicolumn{2}{|c|}{ Melting temperature } & $1300{ }^{\circ} \mathrm{C}$ \\
\hline \multicolumn{2}{|c|}{ Density } & $6.45 \mathrm{~g} / \mathrm{cm}^{3}$ \\
\hline \multirow{2}{*}{ Electrical resistance } & Austenite & $82 \mathrm{~mW} \times \mathrm{cm}$ \\
\cline { 2 - 3 } & Martensite & $76 \mathrm{~mW} \times \mathrm{cm}$ \\
\hline \multirow{2}{*}{ Thermal expansion } & Austenite & $11 \times 10^{-6} \mathrm{~m} /{ }^{\circ} \mathrm{C}$ \\
\cline { 2 - 3 } & Martensite & $6.6 \times 10^{-6} \mathrm{~m} /{ }^{\circ} \mathrm{C}$ \\
\hline \multirow{2}{*}{ Thermal conductivity } & Austenite & $0.18 \mathrm{~W} / \mathrm{cm} \times{ }^{\circ} \mathrm{C}$ \\
\cline { 2 - 3 } & Martensite & $0.85 \mathrm{~W} / \mathrm{cm} \times{ }^{\circ} \mathrm{C}$ \\
\hline \multicolumn{2}{|c|}{ Thermal capacity } & $0.077 \mathrm{cal} / \mathrm{g} \times{ }^{\circ} \mathrm{C}$ \\
\hline \multirow{2}{*}{ Elasticity modulus } & Austenite & $75-83 \mathrm{GPa}$ \\
\cline { 2 - 3 } & Martensite & $28-41 \mathrm{GPa}$ \\
\hline \multirow{2}{*}{ Yield strength } & Austenite & $195-690 \mathrm{MPa}$ \\
\cline { 2 - 3 } & Martensite & $70-140 \mathrm{MPa}$ \\
\hline \multicolumn{2}{|c|}{ Maximum tensile strength } & $754-960 \mathrm{MPa}$ \\
\hline \multicolumn{2}{|c|}{ Transformation temperature } & $-100-110{ }^{\circ} \mathrm{C}$ \\
\hline Latent heat during transformation & $167 \mathrm{~kJ} / \mathrm{kg} \times$ atom \\
\hline \multicolumn{2}{|c|}{ Shape memory strain } & $8.5 \% \mathrm{max}$. \\
\hline
\end{tabular}

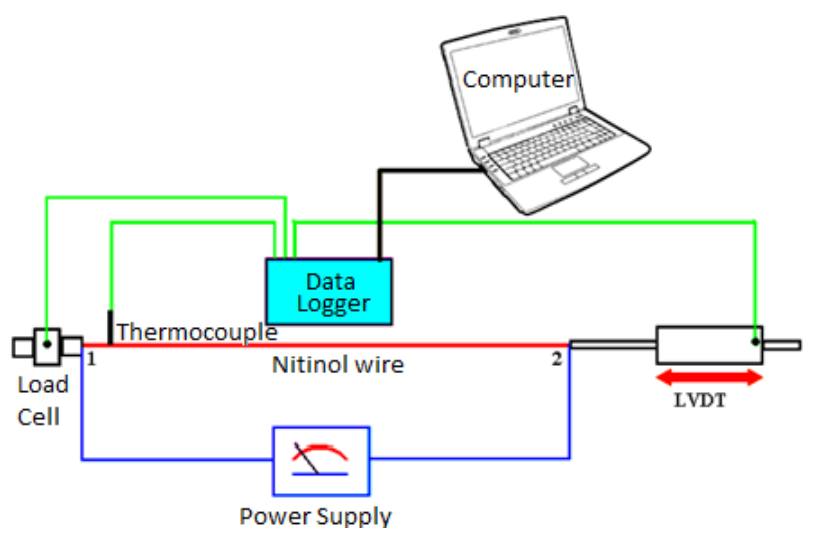

Fig. 5. The experimental setup for the measurement of the NiTi wire

\section{Evaluation}

In the first step of the experimental procedure, the NiTi wire is heated up with electrical power applying on it while its way of lengthening is blocked. As seen from the Fig. 6, even a thin wire with a $0.3 \mathrm{~mm}$ diameter can be implemented as an actuator in system design to produce forces up to $25 \mathrm{~N}$.

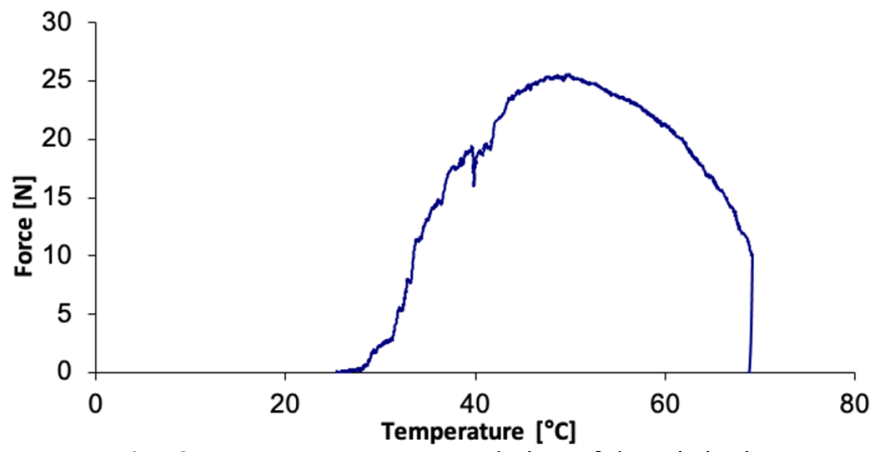

Fig. 6. Force to temperature relation of the NiTi wire 


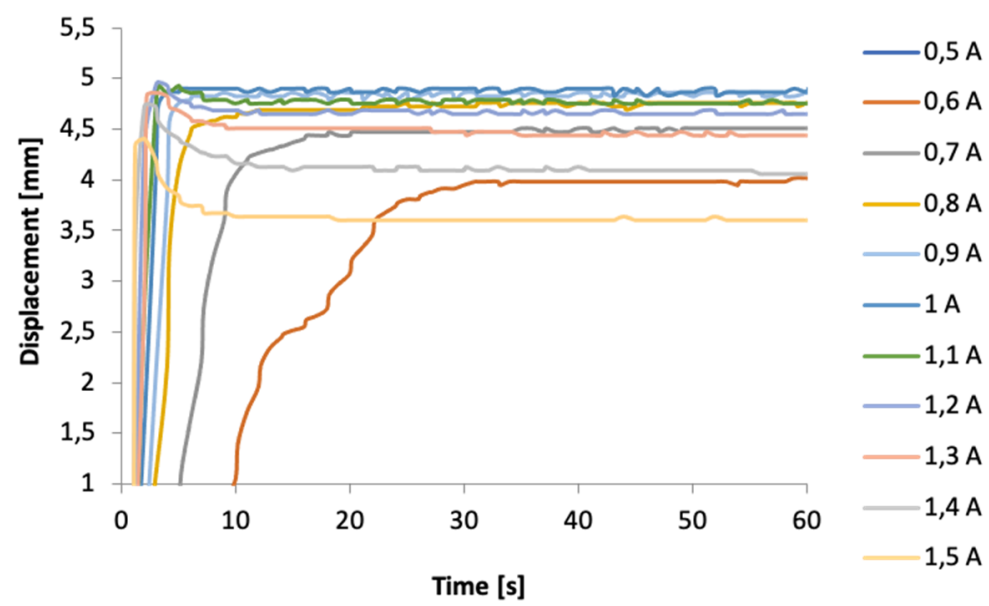

Fig. 7. Displacement values with time of the SMA NiTi wire for different current values
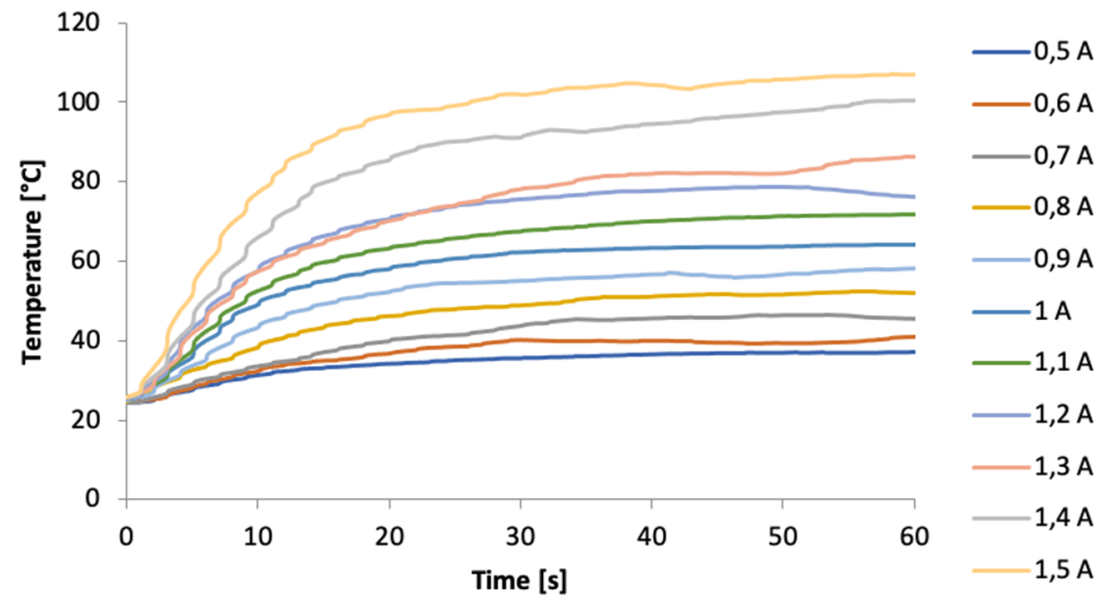

Fig. 8. Temperature change values with time of the SMA NiTi wire for different current values

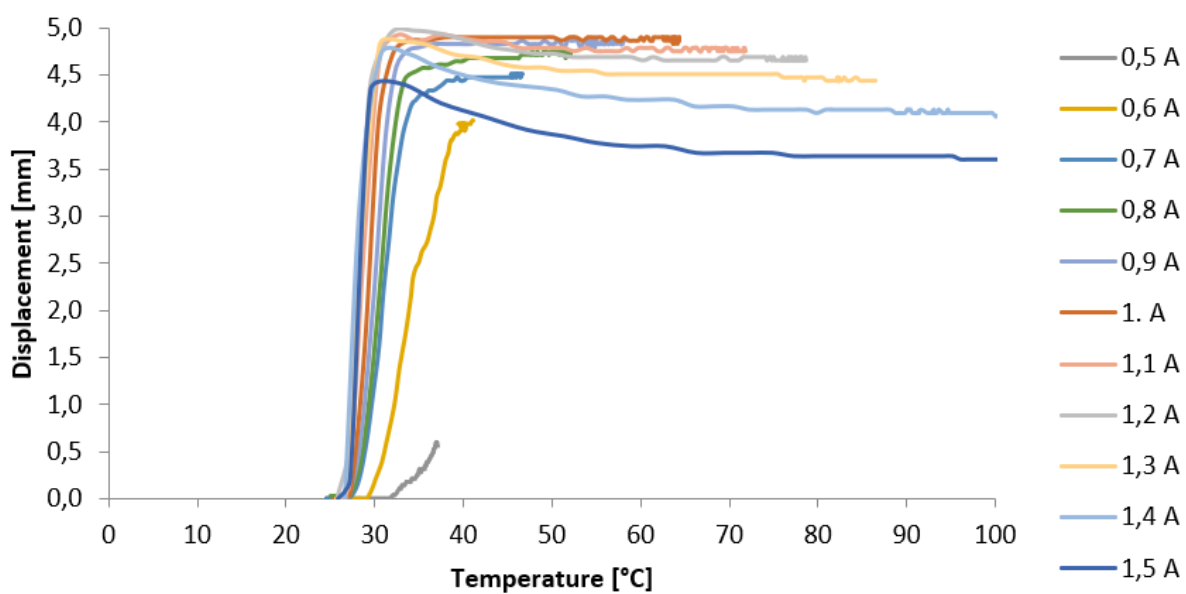

Fig. 9. Displacement to temperature change of the NiTi SMA wire for different current values

In the second step of the experimental procedure, the displacement with respect to varying electrical current flow is observed. Electrical current from $0.5 \mathrm{~A}$ to $1.5 \mathrm{~A}$ was gradually applied 
to the NiTi wire, and the following corresponding data are logged: The displacement over time with for different current values are given in Fig. 7 and the temperature change with time with for different current values are given in Fig. 8.

The displacement to temperature relation of the SMA NiTi wire is given in Fig. 9. As a result of internal austenite phase transform of the SMA NiTi wire, Fig. 9 shows that it can be used as a force and/or linear actuator. As seen from Fig. 9, the displacements are more effective at low currents. For example, while there is a $0.6 \mathrm{~mm}$ displacement at $36{ }^{\circ} \mathrm{C}$ under $0.5 \mathrm{~A}$ current, the displacement is around $4 \mathrm{~mm}$ at $41{ }^{\circ} \mathrm{C}$ under 0.6 A current. This keeps the shape change low because the temperature value occurring at low current is smaller than the austenite start temperature of the wire. Moreover, as a result of the martensite - austensite phase transformation with temperature difference, the resistance of the wire changes since the microstructure of NiTi changes. The resistance to temperature relation for the same set of current values are given in Fig. 10.

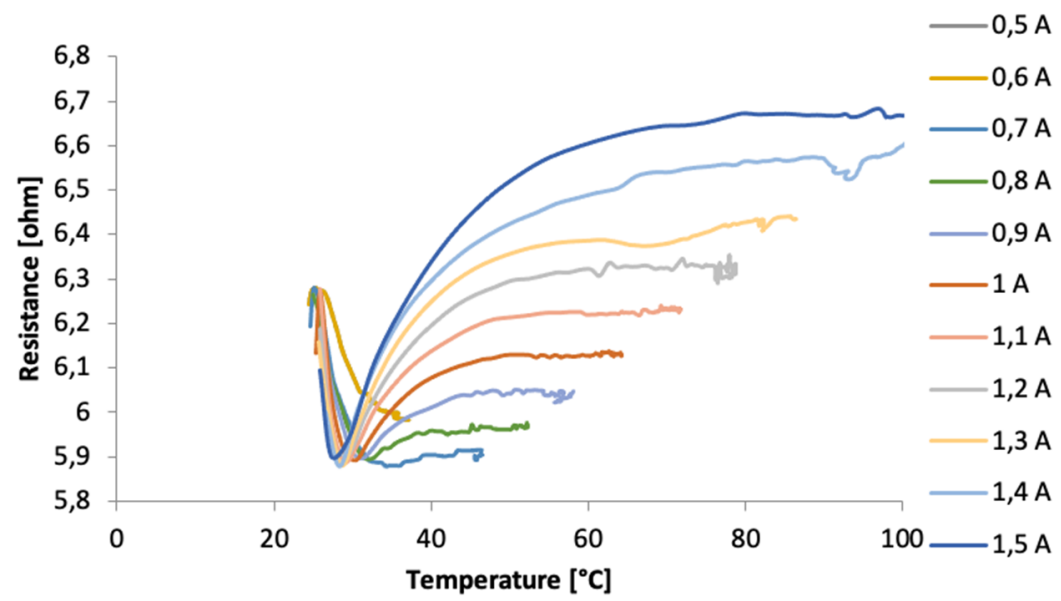

Fig. 10. Resistance change to temperature change of the NiTi SMA wire for different current values

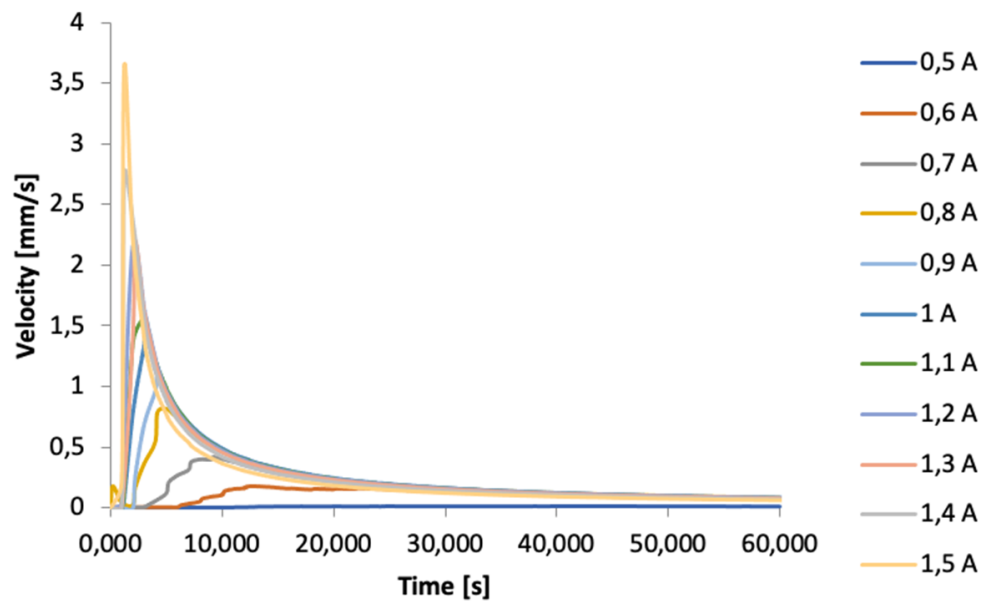

Fig. 11. Displacement velocity values of the NiTi SMA wire with time for different current values

As seen from the Fig. 9 and Fig. 10, SMA materials start to its austenite phase transformation at $25{ }^{\circ} \mathrm{C}$ temperature, and meanwhile, the electrical resistance reaches it minimum value.

The displacement velocity of the SMA NiTi wire with time for the same set of electrical current values are given in Fig. 11. The resulting speed changes draw attention considering its small size and lightweight. From Fig. 11, it can be seen that the velocity can reach up to $3.7 \mathrm{~mm} / \mathrm{s}$ with $1.5 \mathrm{~A}$ 
current.

\section{Conclusions}

In this study, the behavior of the shape memory alloy nickel titanium wire under electric current was investigated by the experimental setup. As soon as the material reaches to the $A_{S}$ (Austenite initial temperature) temperature, phase transformations occur in its internal structure and tries to return to its original shape. $A_{S}$ can be seen from the graphical results, the wire becomes active at a certain temperature. As the current value increases, the displacement and velocity values of the wire increase depending on the rate of increase in the temperature value. However, at low currents, the wire does not respond until it reaches the $A_{S}$ temperature, and the cooling time of the heated wire up to the martensite phase is a disadvantage for actuator applications.

These types of materials offer an advantage over other actuators depending on the force it generates against small dimensions. These materials are especially important in anthropomorphic robot applications in terms of using them as artificial muscles. Particularly in robot hand applications, the dimensional volume and low weight of the wires will allow them to work under low inertia masses. If the internal structures of these materials can be controlled, using them as actuators in many applications will provide an advantage over other systems in terms of performance criteria. As seen in our study, the force and displacement data generated by the wire are sufficient for many actuator applications. It is thought that this material can be used frequently in applications such as artificial muscles, robotic applications and temperature control of the system.

\section{References}

[1] Atasoy A., et al. Anthropomorphic dexterous prosthetic hand: mechanical design. 37th Annual International Conference of the IEEE Engineering in Medicine and Biology Society, 2015.

[2] Toptaş E., Akkuş N. Şekil hafizalı alaşımlar ve endüstriyel uygulamaları. Makine Teknolojileri Elektronik Dergisi, Vol. 4, 2007, p. 15-22, (in Turkish).

[3] Yuan H., et al. A review of rotary actuators based on shape memory alloys. Journal of Intelligent Material Systems and Structures, Vol. 28, Issue 14, 2017, p. 1863-1885.

[4] Zhang Y., Xu X. Transformation temperature predictions through computational intelligence for NiTi-based shape memory alloys. Shape Memory and Superelasticity, Vol. 6, 2020, p. 374-386.

[5] Otsuka K., Kakeshita T. Science and technology of shape-memory alloys: new developments. Mrs Bulletin, Vol. 27, Issue 2, 2002, p. 91-100.

[6] Nohouji H. S., Hamedi M., Salehi M. Modeling, Validation, and testing of a Ti-49.8\% Ni shape memory actuator. Journal of Intelligent Material Systems and Structures, Vol. 26, Issue 16, 2015, p. 2196-2204.

[7] Gu H., et al., Phase engineering and supercompatibility of shape memory alloys. Materials Today, Vol. 21, Issue 3, 2018, p. 265-277.

[8] Hannequart P., et al. The potential of shape memory alloys in deployable systems - a design and experimental approach. Humanizing Digital Reality, Springer, 2018, p. 237-246.

[9] Sivakumar S., et al. A review of the constitutive models for shape memory alloys. International Conference on Smart Materials Structures and Systems, Bangalore, India, 2005.

[10] Roshan T., et al. Development of a PID based closed loop controller for shape memory alloy actuators. Moratuwa Engineering Research Conference, 2018.

[11] Bhardwaj A., et al. Characterization of mechanical and microstructural properties of constrained groove pressed nitinol shape memory alloy for biomedical applications. Materials Science and Engineering: C, Vol. 102, 2019, p. 730-742.

[12] Huang W. Shape Memory Alloys and Their Application to Actuators for Deployable Structures. Ph.D. Thesis, University of Cambridge, 1998.

[13] Conrad K., et al. Staggered nitinol wire actuator array for high linear displacement and force-to-mass ratio. Critical Reviews ${ }^{\mathrm{TM}}$ in Biomedical Engineering, Vol. 47, Issue 2, 2019, p. 121-129.

[14] Atasoy A., et al. 24 DOF EMG controlled hybrid actuated prosthetic hand. 38th Annual International Conference of the IEEE Engineering in Medicine and Biology Society, 2016. 
[15] Atasoy A., et al. Biomechanical design of an anthropomorphic prosthetic hand. 7th IEEE International Conference on Biomedical Robotics and Biomechatronics, 2018.

[16] Kadir M. R. A., et al. A multi-segmented shape memory alloy-based actuator system for endoscopic applications. Sensors and Actuators A: Physical, Vol. 296, 2019, p. 92-100.

[17] Fernandes D. J., et al. Understanding the shape-memory alloys used in orthodontics. ISRN dentistry, 2011, p. 132408.

[18] Abubakar R. A., Wang F., Wang L. A review on Nitinol shape memory alloy heat engines. Smart Materials and Structures, Vol. 30, Issue 1, 2020, p. 013001.

[19] Shishegaran A., et al. Performance of a novel bent-up bars system not interacting with concrete. Frontiers of Structural and Civil Engineering, Vol. 13, Issue 6, 2019, p. 1301-1315.

[20] Shishegaran A., Rahimi S., Darabi H. Introducing box-plate beam-to-column moment connections. Vibroengineering Procedia, Vol. 11, 2017, p. 200-204.

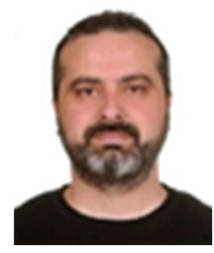

Ersin Toptas received Ph.D. degree in Institute of Pure and Applied Sciences from Marmara University, Istanbul, Turkey, in 2015. Now he is with the Faculty of Technology, Marmara University. His current research interests are mechanical design, computer aided analysis, SMA and composites.

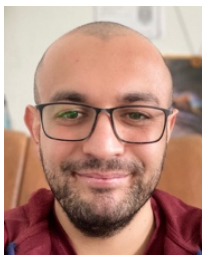

Mehmet Fatih Celebi received M.Sc. degree in Electrical and Electronics Engineering from Marmara University, Istanbul, Turkey, in 2017. Now he is a Ph.D. candidate and works as research assistant in the same university. His current research interests include circuit analysis and design, control, and soft robotics.

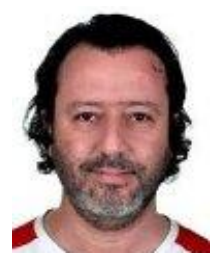

Sezgin Ersoy is an Associate Professor of Mechatronics Engineering and Material Science. After graduating from Marmara University, he became a faculty member at the same university. His publications include a variety of efforts to understand changes in automotive mechatronics, polymer science and biomedical technologies. He was granted fellowship at the TUBITAK at Bourgogne University ISAT and spent one year as a visiting fellow there to study several projects between 2014 through 2015. He is the author of chapter Science Education in a Rapidly Changing World, USA 2011, and the author in Acoustic Properties of BioMaterials, Stuttgart, 2010. He has two science national awards and is an Editorial Member of several scientific journals. 